\title{
A Comparison of Two 85-GHz SSM/I Ice Concentration Algorithms With AVHRR and ERS-2 SAR Imagery
}

\author{
Stefan Kern, Lars Kaleschke, and David A. Clausi, Member, IEEE
}

\begin{abstract}
Sea ice concentrations obtained with two algorithms from Special Sensor Microwave/Imager (SSM/I) data are compared to spaceborne visible/infrared and active microwave imagery for the Greenland Sea in Spring. Both algorithms, the ARTIST Sea Ice algorithm (ASI) and the SEA LION algorithm (SLA), utilize 85-GHz SSM/I brightness temperatures with a spatial resolution of $15 \mathrm{~km} \times 13 \mathrm{~km}$. Ice concentrations obtained from Advanced Very High Resolution Radiometer (AVHRR) infrared data in cloud-free areas are underestimated by SLA and ASI ice concentrations by $3.6 \%$ and $8.3 \%$ (correlation coefficients of 0.90 and 0.91$)$. Ice concentrations estimated from texture classified ERS-2 synthetic aperture radar (SAR) images by assigning experience-based ice concentrations to ice-type classes are overestimated by SLA and ASI ice concentrations by $4.4 \%$ and $1.5 \%$ (correlation coefficients of 0.84 and 0.77 ). However, omitting low/high ice concentrations forming up to $80 \%$ (AVHRR) and $60 \%$ (SAR) of the entire dataset reveals a significantly different statistic. For instance, the correlation between AVHRR and SLA and ASI ice concentrations drops to 0.77 and 0.70 , respectively. All presented techniques to obtain ice concentrations need improvement and future developments should involve larger datasets. However, with care, both algorithms can be used to obtain reasonable ice concentration maps with a $12.5 \mathrm{~km} \times 12.5 \mathrm{~km}$ grid-cell size.
\end{abstract}

Index Terms-Arctic regions, algorithms, microwave radiometry, neural network application, sea ice, synthetic aperture radar (SAR).

\section{INTRODUCTION}

$\mathbf{S}$ EA ICE SIGNIFICANTLY affects heat fluxes between the ocean and the atmosphere [1]. Sea ice representation in numerical climate models is still an active research topic [2] requiring long-term large-scale sea ice observations. These can be provided by remote sensing satellite sensors such as the Special Sensor Microwave/Imager (SSM/I) onboard the Defense Meteorological Satellite Program (DMSP) spacecraft, which has acquired data since 1987. It is equipped with dual-polarized (vertical and horizontal) channels at 19,37 , and $85 \mathrm{GHz}$ and one

\footnotetext{
Manuscript received September 30, 2002; revised June 20, 2003. This work was supported by the European Union under Contracts ENV4-CT97-0415 (DG12-ESCY), ENV4-CT97-0497-0487 (DG12-ESCY), and EVG1-CT-2000-00029, by the German Science Foundation (DFG), and by the University of Hamburg/D. Stammer.

S. Kern is with the Institute of Oceanography, University of Hamburg, 22529 Hamburg, Germany (e-mail: kern@ifm.uni-hamburg.de).

L. Kaleschke is with the Institute of Environmental Physics and Remote Sensing, University of Bremen, D-28334 Bremen, Germany (e-mail: lars@seaice.de).

D. A. Clausi is with the Systems Design Engineering, University of Waterloo, Waterloo, ON, N2L 3G1, Canada (e-mail: dclausi@uwaterloo.ca).

Digital Object Identifier 10.1109/TGRS.2003.817181
}

vertically polarized channel at $22 \mathrm{GHz}$. SSM/I orbit and scan geometry allow monitoring polar regions poleward of $60^{\circ} \mathrm{N}$ or $60^{\circ} \mathrm{S}$ almost entirely during one day [3]. Data coverage improves when using all three current DMSP satellites.

Ice concentration maps can be generated from SSM/I data using well known algorithms such as the NASA TEAM algorithm (NTA, [4]) or the Comiso Bootstrap algorithm (CBA) [5]. Spatial resolution of such maps is determined by sampling distance and field-of-view (FOV) associated with the lowest SSM/I frequency used. This is usually the $19-\mathrm{GHz}$ channel (sampling distance: $25 \mathrm{~km}$, FOV: $69 \mathrm{~km} \times 43 \mathrm{~km}$ ). Using the $85-\mathrm{GHz}$ channels (sampling distance: $12.5 \mathrm{~km}$, FOV: $15 \mathrm{~km} \times 13 \mathrm{~km}$ ) would allow resolution improvement by at least a factor of four. Several authors have suggested or already used $85-\mathrm{GHz}$ SSM/I data for sea ice concentration retrieval [6]-[9], or have used $85-\mathrm{GHz}$ data for algorithm enhancement [10].

Sea ice analysis using $85-\mathrm{GHz} \mathrm{SSM} / \mathrm{I}$ data is hampered by a considerably larger weather influence compared to 19- and 37-GHz SSM/I data. The surface wind changes sea surface roughness and thus alters the surface emissivity. Atmospheric water causes a change in atmospheric opacity. Both effects yield a net decrease of the polarization ratio at $85 \mathrm{GHz}$ causing an ice concentration overestimation. The two algorithms compared here for determining ice concentrations using 85-GHz SSM/I data are the ARTIST Sea Ice algorithm [8] (simply referred to as ASI) and the SEA LION algorithm (SLA) [9], [11]. Both of these methods address the weather influence in different ways.

The ice concentration measurements produced by SLA and ASI will be compared to concentrations produced using satellite-based synthetic aperture radar (SAR) and visible/infrared (IR) imagery. The SAR data is generated by the second European Remote Sensing satellite (ERS-2, 5.3 GHz, vertical polarization on transmit and receive), which produces high-resolution imagery $(25 \mathrm{~m} \times 25 \mathrm{~m}$ spatial resolution over an $100 \mathrm{~km}$ $\times 100 \mathrm{~km}$ area). However, temporal coverage is sparse compared to SSM/I. Therefore, despite the much better spatial resolution of SAR data, large-scale ice analysis still has to rely on passive microwave data. Images from the Advanced Very High Resolution Radiometer (AVHRR) are also used to generate ice concentration estimates for comparison to ASI and SLA. Visible, near-IR, and IR bands at 1.1-km resolution are used. For sea ice analysis, however, only AVHRR data of cloud-free areas can be used. Accepted methods for generating ice concentrations using SAR and AVHRR imagery are employed.

The paper proceeds in the following fashion. Section II gives specific details about the image data. Section III describes the al- 
TABLE I

SSM/I Characteristics [3], $f$ : Frequency, $p$ : Polarization, FOV: FIELD-OF-VIEW, SI: SAMPLING INTERVAL

\begin{tabular}{cccc}
\hline$f[\mathrm{GHz}]$ & $p$ & FOV $[\mathrm{km} \times \mathrm{km}]$ & SI $[\mathrm{km}]$ \\
\hline 19.35 & $h, v$ & $69 \times 43$ & 25 \\
\hline 22.235 & $v$ & $50 \times 40$ & 25 \\
\hline 37.0 & $h, v$ & $37 \times 29$ & 25 \\
\hline 85.5 & $h, v$ & $15 \times 13$ & 12.5 \\
\hline
\end{tabular}

gorithms that were used, namely, the SLA and ASI as well as the methods used to derive ice concentration maps using SAR and AVHRR images. Section IV describes and Section V discusses the ice concentration results of the SLA and ASI (using SSM/I data) compared to the thematic maps produced using SAR and AVHRR. Section VI summarizes the results and suggests future applications.

\section{DATA}

Both ASI and SLA are applied to $85-\mathrm{GHz}$ SSM/I data acquired aboard DMSP platform F14 in April 1999 in the Greenland Sea. See Table I for SSM/I channels and associated spatial resolutions and sampling intervals [3]. Data are interpolated into a polar-stereographic grid with $12.5 \mathrm{~km} \times 12.5 \mathrm{~km}$ grid cell size.

The SLA requires atmospheric data as provided by the $\mathrm{Nu}-$ merical Weather Prediction (NWP) model High Resolution Limited Area Model (HIRLAM) of the Danish Meteorological Institute (DMI). In the Greenland Sea, this model has a spatial resolution of $0.15^{\circ} \times 0.15^{\circ}$, which is similar to $85-\mathrm{GHz} \mathrm{SSM} / \mathrm{I}$ data. Model data are also interpolated into the above-mentioned grid.

For the comparison, 16 ERS-2 SAR images acquired in April 1999 in the Greenland Sea have been selected (orbits 20762 , 20805 , and 20 848). SAR images are classified as described in Section III. Also, data of channels 1, 2, and 4 of the Advanced Very High Resolution Radiometer (AVHRR) aboard the NOAA-15 spacecraft are used for comparison.

\section{METHODS}

\section{A. ASI Algorithm}

ASI [8] combines a model for retrieving total ice concentration from SSM/I 85-GHz data proposed by [6] (Svendsen algorithm, SVA) with an ocean mask derived from 19-, 22-, and 37-GHz SSM/I data using the NT algorithm [4] and the weather filter of [12]. The algorithm of [6] is based on a simplified form of the microwave radiative transfer equation

$$
\begin{aligned}
P & =\left(1.1 e^{-\tau}-0.11\right) e^{-\tau}(a C+b) \\
a & =\Delta e_{i} T_{i}-\Delta e_{w} T_{w} \text { and } b=\Delta e_{w} T_{w}
\end{aligned}
$$

where $C$ is the total ice concentration; $P$ is the brightness temperature polarization difference at $85 \mathrm{GHz} ; \Delta e$ is the surface emissivity polarization difference of ice or open water; and $\tau$ is the total atmospheric optical depth. Effective surface temperatures of ice and open water are $T_{i}$ and $T_{w}$, respectively.

The brightness temperature polarization difference at $85 \mathrm{GHz}$ $P=T_{v}-T_{h}$ (where $T_{v}$ and $T_{h}$ are brightness temperatures at vertical and horizontal polarization) is small over ice and large over open water. Assuming that the atmospheric influence can be represented by a smooth function of $C$ between ice and open water the polynomial

$$
C_{\mathrm{ASI}}=1.1-0.00926 P-0.000604 P^{2}+6.438 \cdot 10^{-6} P^{3}
$$

can be used to calculate $C$. The coefficients of (2) as well as tie points of open water and ice are estimated from data of the Arctic Radiation and Turbulence Interaction STudy (ARTIST), conducted in the environment of the Svalbard archipelago in March/April 1998. This has been done by using reference ice concentration data and least square statistics for tie point optimization. This approach is more accurate than the one proposed by [6] relying on minimum and maximum values of some samples.

Weather induced errors of ice concentration estimated with (2) are large for open ocean and relatively small for sea ice due to the higher emissivity of sea ice. Therefore, each pixel $C_{\mathrm{ASI}}$ is set to zero if $C_{\mathrm{NTA}} \leq C_{\text {threshold }}$ where $C_{\mathrm{NTA}}$ is the NTA ice concentration (including the weather filter of [12]). The threshold $C_{\text {threshold }}=5 \%$ masks ice-free areas. A threshold $C_{\text {threshold }}=30 \%$, as given in [8], can be used for removing strong weather influence without the above-mentioned weather filter.

\section{B. Sea Lion Algorithm}

The SEA LION algorithm (SLA) [11] was developed during the project SEA LION (SEa ice in the Antarctic-LInked with OceaN-atmosphere forcing) and uses the normalized brightness temperature polarization difference (also called polarization ratio, $\mathrm{PR} 85$ ) at $85 \mathrm{GHz}$

$$
P_{N}=\frac{T_{v}-T_{h}}{T_{v}+T_{h}} .
$$

Using $P_{N}$ instead of $P$ minimizes the temperature dependence. Brightness temperatures are given by

$$
T_{v}=(1-C) T_{v w}+C T_{v i}, \text { and } T_{h}=(1-C) T_{h w}+C T_{h i}
$$

with $1-C$ and $C$ being fractions of a unit area covered by open water and ice and $T_{v w}, T_{h w}$ and $T_{v i}, T_{h i}$ being tie points of open water and sea ice. At $85 \mathrm{GHz}, P_{N}$ takes values around 0.20 over open water and 0.02 over $100 \%$ ice, almost independently of the ice type [6]. Inserting (4) into (3) and solving for $C$ yields

$$
C=\left(1+\frac{T_{v i}+T_{h i}}{T_{v w}+T_{h w}} \frac{P_{N i}-P_{N}}{P_{N}-P_{N w}}\right)^{-1} .
$$

The quantities $P_{N w}$ and $P_{N i}$ are tie points of open water and ice. They have been estimated from data of all SSM/I overpasses of the Greenland Sea during April 7 to 18, 1999, and therefore reflect average conditions of this period. Ice tie points are estimated using a mask including all pixels where average as well as temporal variability of PR85 are below a certain threshold. The average ensures that only pixels are used where PR85 yields a minimum ice concentration of at least $95 \%$. The temporal variability allows identification of those pixels where the low average PR85 is indeed caused by high ice concentration and not by a frequent weather influence. 
The major difference between ASI and SLA is the correction of $85-\mathrm{GHz}$ SSM/I brightness temperature changes due to the weather influence, quantified by surface wind speed $V$, atmospheric water vapor content $W$, and atmospheric liquid water content $L$. ASI tie points include this weather influence empirically and, therefore, requires no explicit correction of brightness temperatures. For the SLA, $V, W$, and $L$ are either taken from a NWP model (HIRLAM) and/or are taken, over open water only, from low-frequency SSM/I data (19, 22, and $37 \mathrm{GHz})$ [13]-[15]. The MicroWave MODel (MWMOD) [16] is used to quantify the weather influence and to correct brightness temperatures of a known surface (open water or ice) for this influence given by $V, W$, and $L$.

Calculating $C$ with the SLA requires iterations starting with a first-guess of $C$ obtained from uncorrected $P_{N}$ values. In each iteration, an improved weather-influence-corrected $P_{N}$ value is used to calculate an improved $C$ value, which in turn is used to obtain a new modeled value of $P_{N}$. The iterations are stopped after 60 steps or if $\Delta P_{N}$ (the difference between $P_{N}$ and the modeled value of $P_{N}$ ) falls below a threshold of 0.001 ensuring a theoretical retrieval accuracy of $\approx 1 \%$. SLA ice concentrations shown in Section IV are a combination of two SLA runs using either HIRLAM or SSM/I data for the weather influence correction over open water. This has become necessary because $V, W$, and $L$ values derived from SSM/I data are more realistic over open water than NWP model data and thus improve the SLA sea ice analysis. More information about the SLA is given in [11] and [17].

\section{SAR Image Classification}

Compared to SSM/I, ERS-2 SAR data is restricted since it uses only one frequency and one polarization for sending and receiving. In addition, the signal is degraded by the multiplicative speckle noise. The ambiguities in the normalized radar cross section $\sigma^{0}$ general do not allow unique assignments to sea ice types with simple threshold techniques. Moreover, the backscatter of ice-free ocean depends on the wind-speed which can vary considerable in one SAR frame especially in the marginal ice zone (MIZ) [18]. No general automatic algorithm exists for the estimation of sea ice concentration from SAR data.

A supervised classification of ERS-2 SAR sea ice imagery is performed by using texture feature extraction and a neural network. First, the ERS-2 SAR data was calibrated [19]. Then, the linear incidence angle dependence of sea ice backscatter was removed. An average incidence angle dependence (slope) of $\partial \sigma^{0}(\theta) / \partial \theta=-0.3 \mathrm{~dB} /{ }^{\circ}$ was used which was estimated within the overlap of the ascending and descending branch of the orbit [20]. The technique for the slope estimation is similar to that used by [21]. The slope depends on ice type and surface roughness (deformation). The value of $-0.3 \mathrm{~dB} /{ }^{\circ}$ represents an average of predominantly first-year and young ice in the MIZ. The next step is to select appropriate textures features.

Texture, a representation of the spatial relationship of gray levels, is important for computer-assisted interpretation of images. Since SAR imagery contains spatially dependent class characteristics, texture extraction methods have been commonly
TABLE II

Features (F) Derived From the ERS-SAR IMage. Calculation WINDOW SIZE: $n$. NUMBER OF GRAY LEVELS: $G$

\begin{tabular}{clcc}
\hline F & rule & $n$ & $G$ \\
\hline \hline LEE & $f_{1}=$ LEEFILTER $\left(\sigma^{0}(i), N\right)$ & $7 \times 7$ & \\
\hline MEAN & $f_{2}=\sum_{i=1}^{N} i P_{i j}$ & $16 \times 16$ & \\
\hline ENT & $f_{3}=-\sum_{i, j=1}^{G} P_{i j} \log P_{i j}$ & $16 \times 16$ & 8 \\
\hline INV & $f_{4}=\sum_{i, j=1}^{G} \frac{P_{i j}}{|i-j|}$ & $128 \times 128$ & 256 \\
\hline
\end{tabular}

used for discrimination [22], [23]. Of the many existing texture methods, cooccurrence probabilities [24] have been successfully applied to SAR sea ice imagery. As a result, this is the texture feature extraction method of choice used in this paper.

Four different features $\mathbf{f}=\left(f_{1}, f_{2}, f_{3}, f_{4}\right)$ given in Table II are derived from the ERS-2 SAR images using an $n \times n$ window. The first feature is the output of the Lee filter [25]. The Lee technique for additive image noise was applied in a $7 \times 7$ pixel local neighborhood on the $\sigma^{0}$ (in decibels) images. The other three outputs are based on gray level cooccurrence probabilities. The gray level cooccurrence probabilities represent the conditional-joint probabilities $\left(P_{i j}\right)$ of all pairwise combinations of gray levels separated by a distance $r$ and an orientation $\theta$. These probabilities are typically stored in a matrix, often referred to as the gray level cooccurrence matrix or GLCM. Here, the textures are assumed to be rotationally invariant, so, for a given distance $r$, the probabilities are averaged together. Once the probabilities for a given window are known, then statistics are applied to generate the texture features. The statistics used here are mean (MEAN), entropy (ENT), and inverse moment (INV).

Given that remote sensing images tend to be large and given that each pixel requires its own texture feature vector, a fast algorithm was employed. A suitable approach is an iterative framework which is commonly employed in image processing algorithms [26]. Such a method avoids the need to traverse entire GLCMs and, in doing so, significantly minimizes the computational demands. For example, based on trial testing on an separate $2000 \times 2000$ SAR image, the GLCM method required over five times the computational time compared to the iterative method given a window size of $15 \times 15$ and a quantization level of 32. The iterative method requires anywhere from approximately $1 \%$ to $50 \%$ of the computational time of the matrix method, depending on the parameters selected ( $n, G$, statistics).

A supervised neural network learning architecture was used for classification, namely Kohonen's Learning Vector Quantization (LVQ) [27]. LVQ approximates the probability density functions by a set of optimally placed vectors which are called codebook vectors (CV). The codebook is generated by learning from examples of class labeled feature vectors (training data). About 70-200 homogeneous areas of five different surface types were manually selected for each ERS-2 orbit. First-year (FY), grease (GR), brash (BR), and level (LE) ice, as well as open water $(\mathrm{OW})$ regions were discriminated. These areas were used for training and testing of the neural network. The advantage of using a neural network is the adaptiveness, i.e., it can be trained with examples of different appearance, such as calm or wind roughened open water. Best results are obtained if wind speed and direction are almost uniform within the region of interest-a 
TABLE III

Estimated EFFECTIVE ICE CONCENTRATIONS [IN PERCENT] IN THEMATIC SAR MAPS. SEE TEXT FOR MEANING OF COLORS

\begin{tabular}{ccccc}
\hline $\begin{array}{c}\text { Open Water } \\
(\mathrm{OW})\end{array}$ & $\begin{array}{c}\text { Grease } \\
\text { Ice (GR) }\end{array}$ & $\begin{array}{c}\text { Brash } \\
\text { Ice (BR) }\end{array}$ & $\begin{array}{c}\text { Level } \\
\text { Ice (LE) }\end{array}$ & $\begin{array}{c}\text { First-year } \\
\text { Ice (FY) }\end{array}$ \\
\hline 0 & 30 & 90 & 98 & 100 \\
\hline blue & black & green & red & orange \\
\hline
\end{tabular}

TABLE IV

Open Water ANd SEA Ice TIE POINTS [IN Kelvin] OBTAINEd From AVHRR CHANNEL $4 T_{I R}$ MAPS OF DATES GIVEN IN TABLE V

\begin{tabular}{cccc}
\hline & April 10 & April 13 & April 16 \\
\hline$T_{I R, \text { ow }}$ & 269.9 & 270.1 & 269.6 \\
\hline$T_{I R, \text { ic }}$ & 264.8 & 264.7 & 264.9 \\
\hline
\end{tabular}

reasonable assumption when classifying several SAR images neighboring each other. The classification accuracy for training (self consistence) and test (test data not used for training) are 95\% and $88 \%$ for April 10,88\% and $73 \%$ for April 13, and $93 \%$ and $81 \%$ for April 16 .

To give an estimate of the ice concentration using the classified SAR images an average ice concentration value is needed for each of the five classes. These values are given in Table III together with the colors used to display the different ice types in Fig. 3 in Section IV. The values stem from the experience gained during experiments of the 1998 ARTIST in the Svalbard area.

The reader should keep in mind, that these values have not been cross-checked against any in situ data. However, given the resolution of the SAR images used and the typical size of first-year and/or level ice floes, these estimates for these two ice types are quite realistic. First-year ice contains a small fraction of multiyear ice (below 20\%). Typical sizes of ice floes or floe fragments of brash ice, however, are small, and therefore the uncertainty of the ice concentration estimate for this ice type is larger-but still difficult to determine. Grease ice contains a consolidated suspension of ice crystals in water, acting as precursor for the development of pancake ice. Certainly, the estimate of $30 \%$ for grease ice marks the lower end of possible ice concentrations.

\section{Ice Concentration From AVHRR Imagery}

AVHRR imagery can be used to estimate the ice concentration with a spatial resolution of $1 \mathrm{~km} \times 1 \mathrm{~km}$ [28], [29]. Appropriate methods use the radiance measured at AVHRR channels 1 and $2(0.58-0.68$ and $0.72-1.10 \mu \mathrm{m})$ and/or the IR brightness temperature (IR temperature or $T_{\mathrm{IR}}$, henceforth) measured at AVHRR channel $4(10.3-11.3 \mu \mathrm{m})$, depending on ice type and time of the year. During winter and spring, for instance, freezing conditions prevail. Consequently, the IR temperature contrast between open water and ice is large. Here, AVHRR data acquired in April 1999 are used together with a tie point method based on AVHRR channel 4 IR temperatures [28], [30]. Tie points (see Table IV) are estimated as follows.

i) Generate a map of AVHRR channel 1 and channel 2 percent albedo and AVHRR channel $4 T_{\mathrm{IR}}$ (maps I, II, and III). Prelaunch slopes and intercepts as well as conversion coefficients as given in the National Oceanic and
Atmospheric Administration (NOAA) LM User's Guide [31] are used. ${ }^{1}$

ii) Apply a cloud-mask by combining maps I and II.

iii) Identify and mark ice floes in map I located as close as possible to open water and, according to the respective $T_{\mathrm{IR}}$ value, belonging to gray or gray-white ice.

iv) From these floes, take the average AVHRR channel $4 T_{\mathrm{IR}}$ value as the AVHRR ice tie point $T_{\mathrm{IR} \text {,ic }}$.

v) Identify and mark areas in map I located as close as possible to the ice edge revealing a radiance typical of open water.

vi) From these areas take the average AVHRR channel $4 T_{\mathrm{IR}}$ value as the AVHRR open water tie point $T_{\mathrm{IR} \text {,ow }}$.

All of these steps are done for each AVHRR image. Respective tie points are listed in Table IV.

Finally, the AVHRR ice concentration $C_{\mathrm{AVHRR}}$ is calculated as follows:

$$
\begin{aligned}
C_{\mathrm{AVHRR}} & =100 \% \text { for } T_{\mathrm{IR}}<T_{\mathrm{IR}, \mathrm{ic}} \\
C_{\mathrm{AVHRR}} & =\frac{T_{\mathrm{IR}}-T_{\mathrm{IR}, \mathrm{ow}}}{T_{\mathrm{IR}, \mathrm{ic}}-T_{\mathrm{IR}, \mathrm{ow}}} \text { for } \\
T_{\mathrm{IR}, \mathrm{ic}} & \leq T_{\mathrm{IR}} \leq T_{\mathrm{IR}, \mathrm{ow}} \\
C_{\mathrm{AVHRR}} & =0 \% \text { for } T_{\mathrm{IR}}>T_{\mathrm{IR}, \mathrm{ow}} .
\end{aligned}
$$

Neither percent albedo nor $T_{\mathrm{IR}}$ are corrected for incidence angle variation or atmospheric attenuation. This is not required because on the one hand data of channel 1 and 2 are only used to select appropriate areas for tie point estimation and to generate a qualitative cloud mask without using absolute values. On the other hand, tie points and $T_{\mathrm{IR}}$ values are similarly influenced by incidence angle variation and atmospheric attenuation leading to a consistent bias.

This method has some shortcomings. First, the cloud masking scheme might fail to remove all clouds. Clouds mimic the surface and depending on whether the surface is warmer or colder than the clouds, the ice concentration can be under- or overestimated. Second, the method assumes that below (above) a certain $T_{\mathrm{IR}}$ value the AVHRR pixel is entirely covered by ice (open water). Subpixel-scale distributions of open water and ice cannot be addressed. A mixture of thick, cold small first-year ice floes and open water, for instance, may cause an IR temperature well below the ice tie point $T_{\mathrm{IR} \text {,ic }}$ despite a notable open water fraction. An ice concentration overestimation would result. Finally, thin ice can cause ice concentration underestimation due to its rather high IR temperature compared to thicker ice.

\section{RESULTS}

ASI and SLA have been used to calculate Greenland Sea ice concentrations for days given in Table V. These SSM/I $12.5 \mathrm{~km}$ $\times 12.5 \mathrm{~km}$ ice concentration $\left(C_{\mathrm{SSMI}}\right)$ maps have been quantitatively compared with NOAA-15 AVHRR visible/IR imagery and with classified ERS-2 SAR images (thematic SAR maps) acquired on the same days. AVHRR maps have been interpolated into a $1 \mathrm{~km} \times 1 \mathrm{~km}$ polar-stereographic fine-mesh version of the grid used at the National Snow and Ice Data Center (NSIDC) [32]. For the thematic SAR maps, latitude/longitude

\footnotetext{
${ }^{1}$ Available online at http://www2.ncdc.noaa.gov/docs/klm/index.htm.
} 
TABLE V

AVHRR, ERS-2 SAR, AND SSM/I OVERPASS TIMES (UTC) USED IN THIS STUDY

\begin{tabular}{cccc}
\hline & April 10 & April 13 & April 16 \\
\hline AVHRR & $17: 05$ & $14: 20$ & $18: 13$ \\
\hline SSM/I & 17 & 17 & 18 \\
\hline \hline SAR & $12: 37$ & $12: 43$ & $12: 49$ \\
\hline SSM/I & 16 & 17 & 16 \\
\hline
\end{tabular}

values of this grid have been interpolated to a spatial resolution of $250 \mathrm{~m} \times 250 \mathrm{~m}$, first. Second, SAR corner and center coordinates are used to generate latitude/longitude pairs for each pixel of the SAR map at the same resolution. Third, by searching for the minimum difference between both latitude/longitude arrays, each pixel of the interpolated SSM/I grid is assigned the corresponding value of the SAR map using the drop-into-the-bucket method. Fig. 1(a) shows the region of interest together with a typical example of an AVHRR IR temperature image superimposed with colocated SLA ice concentration iso-lines. The colored rectangles denote subareas used in the comparison.

\section{A. AVHRR Versus SSM/I Ice Concentration}

A compromise has been made between time difference of AVHRR and SSM/I overpasses and extent of cloud-free areas in AVHRR images when selecting overpasses for the comparison (see Table V). For April 10 and 16, AVHRR and SSM/I overpass times differ by less than $30 \mathrm{~min}$, while for April 13 the time difference is about $3 \mathrm{~h}$. However, the considered area (see Fig. 1(a), large green rectangle) remained cloud-free during that day, and ice drift velocities in this area are about $5 \mathrm{~km}$ per day [33] so that any influence due to the time difference is negligible.

Fig. 1 shows maps of AVHRR channel 1 percent albedo and channel $4 T_{\mathrm{IR}}$ together with the $1 \mathrm{~km} \times 1 \mathrm{~km}$ AVHRR ice concentration $C_{\text {AVHRR }}$ in images Fig. 1(b)-(d) for April 16 (see Fig. 1(a), large green rectangle, for location, and Table $\mathrm{V}$ for times). Both albedo and $T_{\mathrm{IR}}$ reveal a compact ice cover along Greenland and a diffuse ice edge. Several large to vast ice floes as well as some open water/thin ice areas can be identified. There is a clear transition from discernible ice floes with IR temperatures below $263 \mathrm{~K}$ in the northwest (pack ice) to the MIZ in the southeast bordered by ice filaments and open water. Fig. 1(b) exhibits a rather uniform texture with almost no change in the gray level (percent albedo) between more dense ice and ice filaments in the MIZ. Fig. 1(c) indicates a gradual increase of $T_{\mathrm{IR}}$ toward open water to about $266 \mathrm{~K}$ in the MIZ. An abrupt change from $266-269 \mathrm{~K}$ at the transition from dense ice to the ice filaments occurs, followed by another abrupt change at the transition from ice filaments to open water. Accordingly, Fig. 1(d) reveals $100 \%$ ice concentration in the pack ice area-except in the mentioned open water/thin ice areas. These high ice concentrations extend well into the MIZ. Toward the ice edge, ice concentrations drop abruptly to values below $40 \%$ to $50 \%$ northwest of the ice filaments and to $10 \%$ to $30 \%$ in the ice filaments.

The high-resolution ice concentration map has been averaged to $12.5 \mathrm{~km} \times 12.5 \mathrm{~km}$ spatial resolution [Fig. 1(e)] to match the resolution of SSM/I ice concentrations of the ASI [Fig. 1(f)] and of the SLA [Fig. 1(g)]. By comparing Fig. 1(e) with Fig. 1(f) and (g), SLA and ASI ice concentrations $\left(C_{\mathrm{SLA}}\right.$ and $\left.C_{\mathrm{ASI}}\right)$ are lower than $C_{\mathrm{AVHRR}}$ in the pack ice area, especially in the north and in the MIZ. The ice edge is located more to the northwest in both SSM/I ice concentration maps compared to the AVHRR ice concentration.

Similar ice concentration maps have been calculated and compared with each other for the other two days (see Table V). The results have been combined and statistically examined. Fig. 2(a) and (b) show scatterplots of $C_{\mathrm{SSMI}}$ versus $C_{\mathrm{AVHRR}}$. Both SLA and ASI ice concentrations are not in perfect agreement with AVHRR ice concentrations, particular at high ice concentrations, although the regression line slope is about 0.9 and correlation coefficients are around 0.95. For April 10, AVHRR ice concentrations are consequently underestimated by the ASI. For April 13 and 16 (red and blue symbols), the data pairs form a banana-shaped cloud pointing to an underestimation of $C_{\mathrm{AVHRR}}$ at high and low values and an overestimation of $C_{\mathrm{AVHRR}}$ at moderate values. This is most pronounced at high AVHRR ice concentrations, where SSM/I ice concentrations take values down to $20 \%$ (ASI) and $40 \%$ (SLA).

\section{B. SAR Versus SSM/I Ice Concentration}

Sixteen ERS-2 SAR images of orbits listed in Section II (see also Fig. 1(a), yellow, orange and red rectangles) are used for comparison with SSM/I ice concentrations. Time differences between acquisition of selected ERS-2 SAR images and corresponding SSM/I overpasses is about four hours (see Table V). This is considerable given that ice drift is greater in this part of the Greenland Sea compared to the area shown in Fig. 1(b)-(g) [33]. However, the spatial overlap between preceding SSM/I overpasses and selected SAR images is not optimal and reduces the amount of data to be used for a comparison significantly. Therefore, data as given in Table V are used for the statistics, keeping in mind possible errors due to ice drift.

Thematic SAR maps have been derived from all selected SAR images using the scheme described in Section III. In the second step, all pixels within a $12.5 \mathrm{~km} \times 12.5 \mathrm{~km}$ grid cell belonging to one ice type are counted for all ice types of Table III. Thereafter, the sum of the resulting counts is calculated using the ice concentration weights in Table III. Finally, this sum is divided by the number of $1 \mathrm{~km} \times 1 \mathrm{~km}$ grid cells within a $12.5 \mathrm{~km} \times 12.5 \mathrm{~km}$ grid cell to obtain the SAR ice concentration $C_{\mathrm{SAR}}$.

Fig. 3 shows AVHRR channel $4 T_{\mathrm{IR}}$ maps superimposed with thematic SAR maps and $C_{\mathrm{SLA}}$ iso-lines at 5\%,30\%,60\%, and 90\% for April 10 [Fig. 3(a) and (b)] and April 16 [Fig. 3(c) and (d)] (see Table $\mathrm{V}$ for details of dates). The SAR maps of Fig. 3(a) and (b) comprise four SAR frames. The MIZ is characterized by the transition from a compact ice cover with a rather well-defined ice edge in the top third to an increasingly diffuse ice edge further below. According to the SAR map first-year and brash ice (orange and green patches; see Table III for colors) dominate. Therefore, the ice concentration is rather high. There is evidence for this in SLA and ASI ice concentrations with values above $60 \%$ in these areas. The transition from a compact to a diffuse MIZ/ice edge can be identified from SSM/I ice concentrations quite well by means of an increasing interisoline distance. However, only ASI ice concentration iso-lines (5\%, 30\%, 

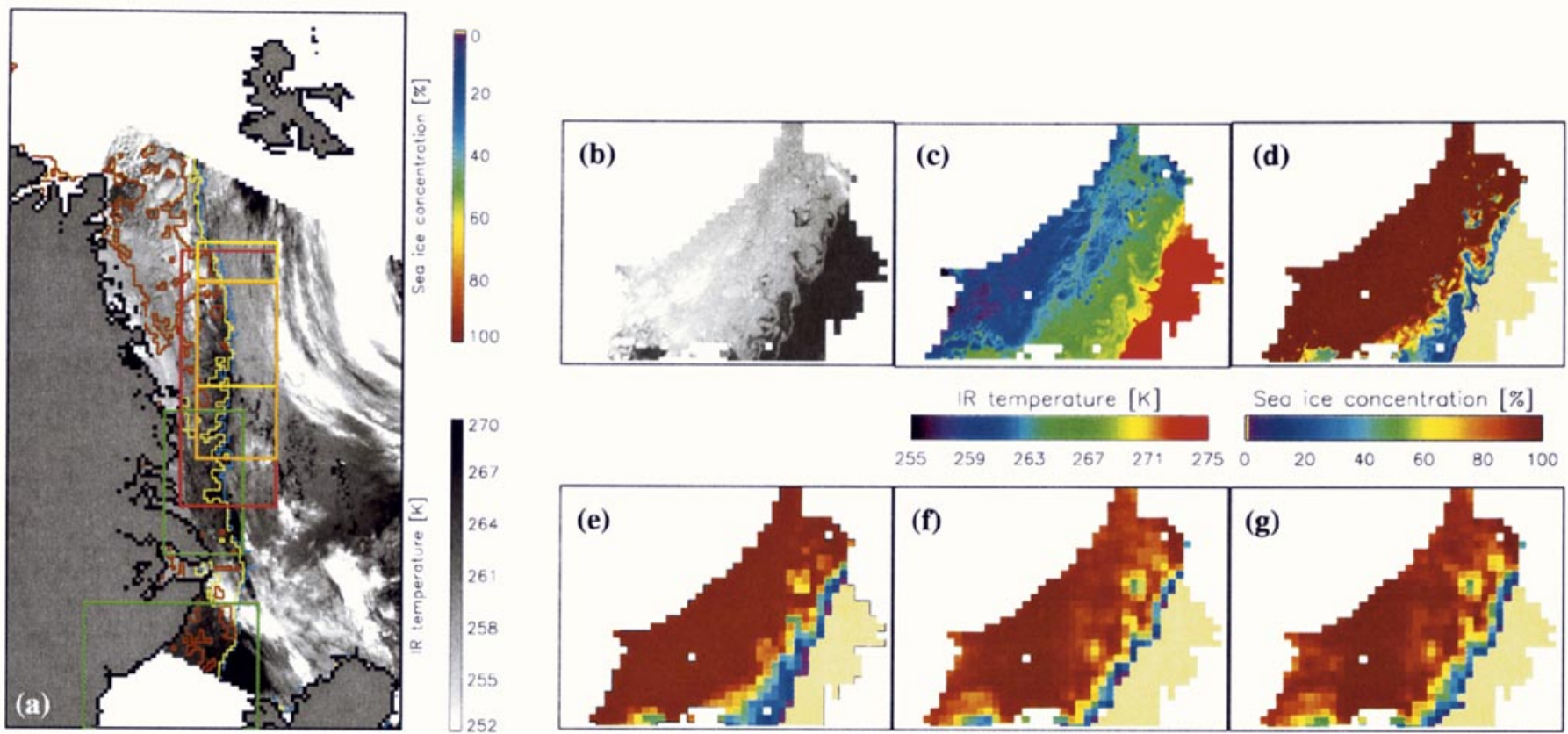

Fig. 1. (a) Overview of area and subareas used for the comparisons: AVHRR channel $4 T_{\mathrm{IR}}$ map of April 16 superimposed with SLA ice concentration iso-lines of April 16. The smaller green rectangle denotes the subarea for the comparison AVHRR versus SSM/I for April 10. The larger green one denotes the subarea for the comparison AVHRR versus SSM/I for April 13 and 16. Other rectangles mark subareas for the comparison SAR versus SSM/I for April 10 (yellow), 13 (orange), and 16 (red). Land, coast, and missing data are gray, black, and white, respectively. (b)-(g) AVHRR images and AVHRR and SSM/I ice concentrations for April 16. (b) and (c) AVHRR channel 1 percent albedo and channel 4 IR temperature. (d) and (e) AVHRR ice concentration $C_{\text {AVHRR }}$ at $1 \mathrm{~km} \times 1 \mathrm{~km}$ and 12.5 $\mathrm{km} \times 12.5 \mathrm{~km}$ spatial resolution, respectively. (f) ASI ice concentration. (g) SLA ice concentration. White areas: clouds/land/missing data.
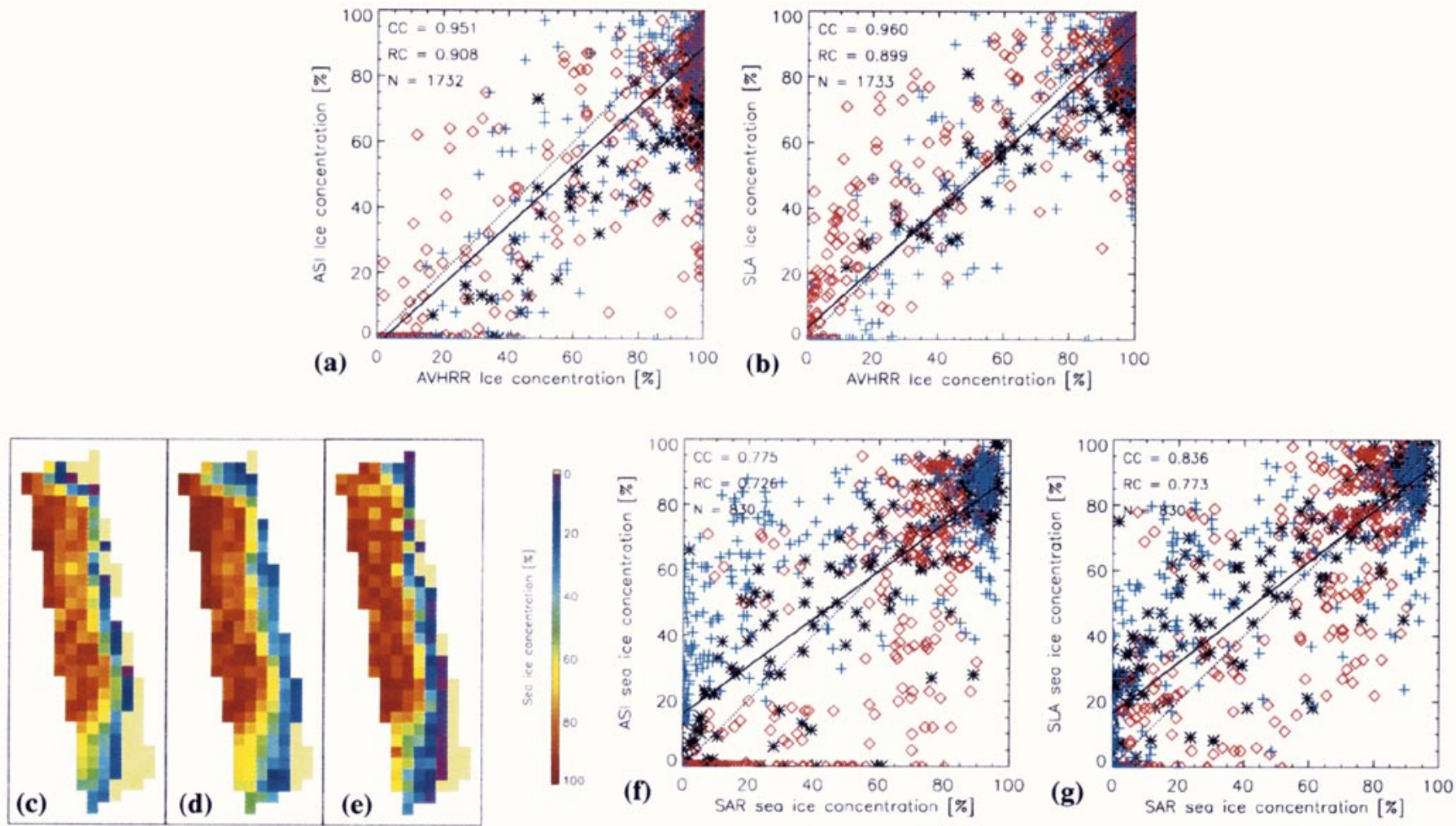

Fig. 2. (a) and (b) SSM/I versus AVHRR ice concentration for dates listed in Table V. (a) $C_{\mathrm{ASI}}$ versus $C_{\mathrm{AVHRR}}$. (b) $C_{\mathrm{SLA}}$ versus $C_{\mathrm{AVHRR}}$. Images (c)-(e) SSM/I and SAR ice concentrations for April 10. (c) ASI ice concentration, bad-weather threshold. (d) SLA ice concentration. (f) SAR ice concentration. Pale yellow is open water (see legend), and white denotes missing data. (f) and (g) SSM/I versus SAR ice concentration for dates given in Table V. (f) $C_{\text {ASI }}$ versus $C_{\mathrm{SAR}} ;(\mathrm{g}): C_{\mathrm{SLA}}$ versus $C_{\mathrm{SAR}}$. Black, red, and blue symbols in (a), (b), (f), and (g) are for April 10, 13, and 16, respectively. CC, RC, and $\mathrm{N}$ are the linear correlation coefficient, the regression coefficient, and the number of data points. Solid lines show the regression of $C_{\mathrm{ASI}}$ versus $C_{\mathrm{AVHRR}}$ in (a), $C_{\mathrm{SLA}}$ versus $C_{\mathrm{AVHRR}}$ in (b), $C_{\mathrm{ASI}}$ versus $C_{\mathrm{SAR}}$ in (f), and $C_{\mathrm{SLA}}$ versus $C_{\mathrm{SAR}}$ in (g). Dotted lines denote perfect agreement. 

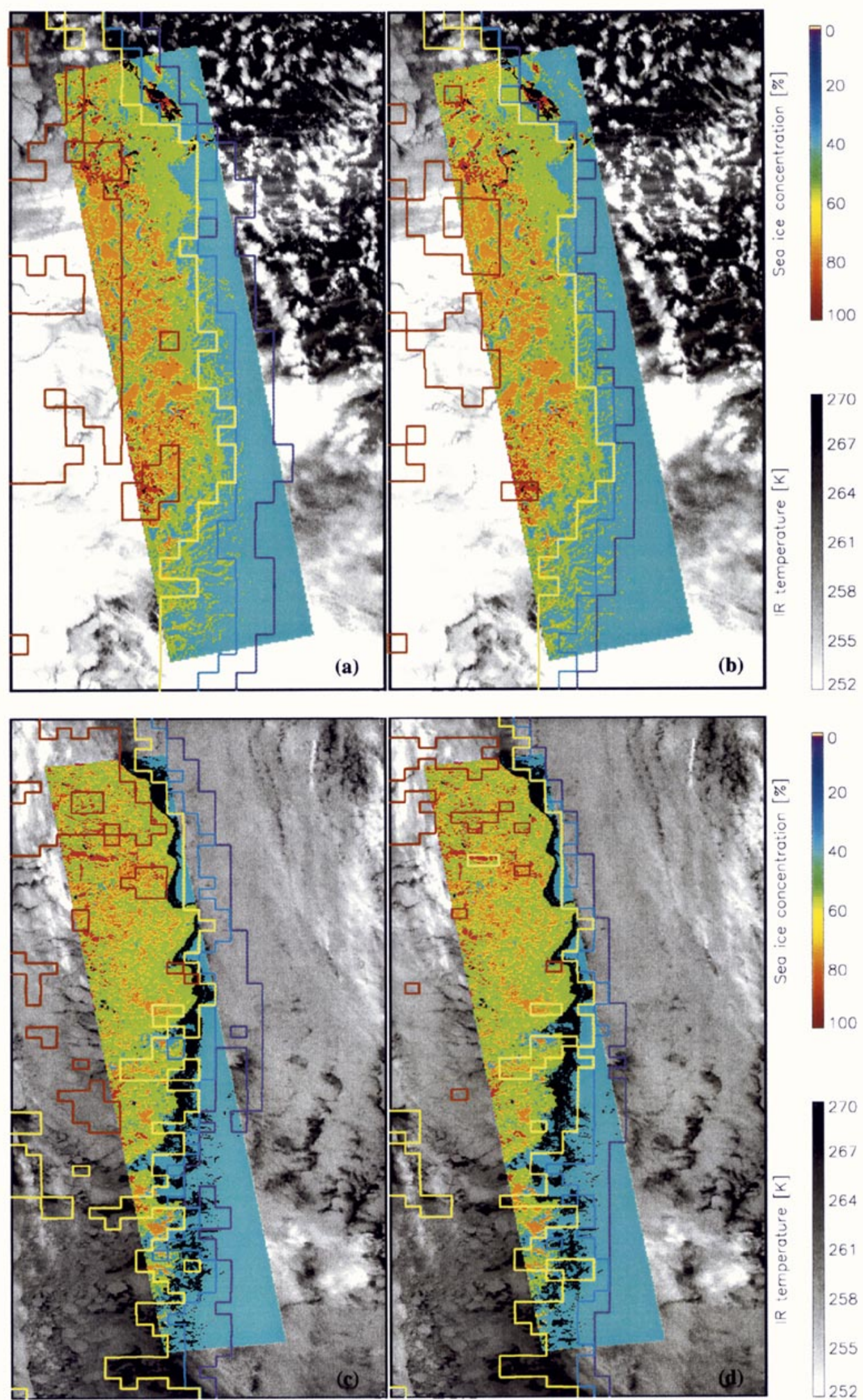

Fig. 3. (a) and (c) AVHRR IR temperature maps superimposed with thematic SAR maps and SLA and (b) and (d) ASI ice concentration iso-lines at 5\%, 30\%, 60\%, and 90\% for April 10 [(a) and (b)] and April 16 [(c) and (d)]. See Table III for colors of SAR maps and Table V for acquisition times. 
and $60 \%$ ) follow the SAR ice edge remarkably well. Respective SLA ice concentration iso-lines tend to align further away from the SAR ice edge.

The SAR maps of Fig. 3(c) and (d) comprise seven SAR frames. Compared to Fig. 3(a) and (b) the situation has changed. According to the SAR map, considerable first-year ice has been converted to brash ice, which dominates (green patches). SLA and ASI ice concentration take values above $60 \%$ in this area. Large areas are covered by grease ice (black patches) aligning along the ice edge. Especially in the bottom third, the MIZ becomes very disrupted with alternating open water and firstyear/brash ice bands. This is evident in the AVHRR channel 4 $T_{\mathrm{IR}}$ map by means of alternating bands of high and low $T_{\mathrm{IR}}$ as well as in SLA and ASI ice concentration maps. However, ice concentration iso-lines of 5\% and $30 \%$ again do not align too well along the SAR ice edge, and SLA ice concentration iso-lines of 5\% and 30\% agree less with the SAR ice edge than those of the ASI [compare Fig. 3(a) and (b)].

Fig. 2(c)-(e) gives an example of SSM/I ice concentrations [Fig. 2(c): ASI; and Fig. 2(d): SLA] in comparison to SAR ice concentration [Fig. 2(e)] for April 10, 1999 (see Table V and Fig. 1(a), yellow rectangle). Size of the shown area is $200 \mathrm{~km}$ $\times 412.5 \mathrm{~km}$. Only SSM/I pixels entirely covered by the SAR map have been used. SLA ice concentrations [Fig. 2(c)] remain above $20 \%$ along almost the entire ice edge, while ASI [Fig. 2(d)] and particularly SAR ice concentrations Fig. 2(e) reveal a smoother transition to open water. Respective SAR images (see Fig. 3) reveal a compact ice pack in the top and a more diffuse ice pack in the bottom. Neither ASI nor SLA ice concentrations confirm this change in ice concentration. The orange-brown area denoting ice concentrations above $80 \%$ is largest in Fig. 2(e) and smallest in Fig. 2(c). Maximum values tend to be highest in Fig. 2(d) and lowest in Fig. 2(c). However, Fig. 2(c) and (d) shows agreement in the ice concentration variation in the high-concentration area. SAR [Fig. 2(e)] shows a different pattern.

Similar ice concentration maps have been calculated and compared with each other for the other days (see Table V). The results are combined and statistically examined. Fig. 2(f) and (g) shows scatterplots of $C_{\mathrm{SSMI}}$ versus $C_{\mathrm{SAR}}$.

SLA and ASI ice concentrations are not in perfect agreement with the SAR ice concentration. Regression and correlation coefficients are 0.78 and 0.84 , respectively. Part of the data form a banana-shaped cloud (blue and red symbols) pointing to an overestimation (underestimation) of $C_{\mathrm{SAR}}$ at low and high values and to an underestimation (overestimation) of $C_{\mathrm{SAR}}$ at moderate ice concentrations for data of April 16 (April 13) by the blue (red) symbols. For April 10, data pairs align more closely along the line of perfect agreement. The overall relationship between $C_{\mathrm{SAR}}$ and $C_{\mathrm{SSMI}}$ is similar for ice concentrations of both algorithms. Both reveal the best correlation for April 10 (ASI: 0.92, SLA: 0.91) and the worst correlation for April 13 (ASI: 0.75, SLA: 0.78).

\section{DISCUSSION}

A primary reason for using $85-\mathrm{GHz}$ SSM/I data for assessing ice concentrations is the spatial resolution improvement compared to other SSM/I frequencies. The ability to monitor smaller open water areas (e.g., leads, polynyas) helps to monitor daily the distribution of bio-geochemical processes. Also, the amount of land-contaminated ice concentrations is reduced and the ability to monitor coastal or flaw polynyas is improved.

Ice concentrations derived from SSM/I 85-GHz data have already been used for navigation [7] and, if prescribed to numerical meso-scale atmospheric models, have proven to notably improve their output [8]. Kaleschke et al. [8] made a qualitative comparison between SAR data, ASI, and NASA Team algorithm (NTA) ice concentrations. The ASI represented the ice concentration gradient across the MIZ more realistically relative to the NTA. SLA ice concentrations have been demonstrated to illustrate finer details than the NTA for Antarctic sea ice [9], [11].

An enhancement of the NTA, the NASA Team 2 algorithm (NT2), was used to mitigate certain snow property influences by Markus and Cavalieri [10]. They have quantitatively intercompared ice concentrations of Comiso Bootstrap algorithm (CBA), NTA, NT2, and AVHRR IR imagery for data of one transect in the Sea of Okhotsk (February 4, 1995) and Ross Sea (August 23, 1993). The NT2 provides more accurate ice concentrations with much less bias than the other two algorithms: correlation coefficients improved from 0.50 (CBA) and 0.65 (NTA) to 0.83 (NT2) in the Ross Sea and from 0.65 (CBA) and 0.71 (NTA) to 0.74 (NT2) in the Sea of Okhotsk. Average differences $C_{\mathrm{AVHRR}}-C_{\mathrm{SSMI}}$ improved from $2.2 \%$ (CBA) and $7.9 \%$ (NTA) to $-0.8 \%$ (NT2) for the Ross Sea and from $-7.2 \%$ (CBA) and $1.6 \%$ (NTA) to $-1.1 \%$ (NT2) in the Sea of Okhotsk.

A first quantitative comparison among NTA, CBA, and SLA ice concentrations, i.e., of ice concentrations obtained at a spatial resolution of $25 \mathrm{~km} \times 25 \mathrm{~km}$ (NTA, CBA, 19- and 37-GHz data) and of $12.5 \mathrm{~km} \times 12.5 \mathrm{~km}$ (SLA, 85-GHz data), with SAR ice concentrations was made for the Greenland Sea by Kern [17]. This was done in the same manner and for the same dates as in this study. CBA (NTA) ice concentrations exceeded SAR ice concentrations on average by $15.5 \pm 19.5 \%(8.5 \pm 18.8 \%)$ with regression and correlation coefficients of 0.552 and $0.832(0.571$ and 0.848 ). In comparison to Table VI, correlation coefficients are similar to SLA results, while regression coefficients are significantly smaller compared to SLA and ASI results. Also, using the SLA or ASI, average differences between SAR and SSM/I ice concentrations are much smaller with a comparable standard deviation compared to CBA and NTA. The focus of this paper, however, is the quantitative intercomparison of SLA and ASI, both based on SSM/I 85-GHz data, with SAR and AVHRR ice concentrations.

Table VI summarizes the statistics for comparing AVHRR versus SSM/I ice concentration and SAR versus SSM/I ice concentration of all dates given in Table V. It contains correlation coefficients (CC), regression coefficients (RC), the root-meansquare error (RMS), and bias (BIAS) for this regression, and the number of data points used $(N)$. Columns denoted by DIFF contain the average difference \pm one standard deviation. Landand cloud-contaminated pixels (AVHRR) or pixels not entirely covered by the SAR maps (SAR) have been omitted.

\section{A. AVHRR Versus SSM/I Ice Concentration}

The correlation coefficients of SLA and ASI with respect to AVHRR are each very strong (0.95) as well as the regression 
TABLE VI

CORRELATION COEFFICIENT (CC), REgRESSION COEFFICIENT (RC), REgRESSION ROOT-MEAN-SQUARE ERROR (RMS), AND REGRESSION BIAS (BIAS), NUMBER of Data Points Used (N), AND AVERAGe ICE CONCENTRATION DifFERENCE \pm ONE STANDARD DEVIATION (DIFF) OF THE COMPARISON SSM/I VERSUS AVHRR OR SAR ICE CONCENTRATION OF ALl DATES GIVEN IN TABLE V

\begin{tabular}{r|cccccc}
\hline \hline $0-100 \%$ & CC & RC & RMS [\%] & N & BIAS [\%] & DIFF [\%] \\
\hline \hline SLA vs. AVHRR & 0.961 & 0.900 & 10.9 & 1733 & 3.3 & $3.6 \pm 11.6$ \\
\hline ASI vs. AVHRR & 0.952 & 0.908 & 12.2 & 1732 & -1.9 & $8.3 \pm 12.8$ \\
\hline \hline $6-94 \%$ & & & & & & \\
\hline \hline SLA vs. AVHRR & 0.774 & 0.658 & 15.3 & 323 & 21.9 & $-2.0 \pm 18.1$ \\
\hline ASI vs. AVHRR & 0.701 & 0.744 & 18.4 & 284 & 8.4 & $8.7 \pm 19.5$ \\
\hline \hline \hline 0 - 100\% & CC & RC & RMS [\%] & N & BIAS [\%] & DIFF [\%] \\
\hline \hline SLA vs. SAR & 0.837 & 0.774 & 18.4 & 830 & 16.3 & $-4.4 \pm 20.2$ \\
\hline ASI vs. SAR & 0.775 & 0.727 & 21.5 & 830 & 15.9 & $-1.5 \pm 23.7$ \\
\hline \hline 11 - 89\% & & & & & & \\
\hline \hline SLA vs. SAR & 0.480 & 0.391 & 18.1 & 348 & 38.9 & $-4.8 \pm 23.8$ \\
\hline ASI vs. SAR & 0.373 & 0.311 & 19.4 & 355 & 44.2 & $-3.2 \pm 26.0$ \\
\hline \hline
\end{tabular}

coefficients (0.90). Average differences are acceptable for the SLA (3.6\%) and elevated for the ASI (8.3\%), each with a standard deviation around $12 \%$. The RMS error of the regression compares with the standard deviations (also $\approx 12 \%$ ). Emery et al. [30] reported differences for a comparison of NTA and CBA ice concentrations $\left(C_{\mathrm{NTA}}\right.$ and $\left.C_{\mathrm{CBA}}\right)$ with AVHRR ice concentrations in the Fram Strait for March 24, 1989, of -1.3\% and $0.8 \%$ for NTA and CBA, respectively, with a standard deviation around 5\%. A comparison between $C_{\mathrm{NTA}}$ and $C_{\mathrm{CBA}}$ with ice concentrations obtained from LANDSAT imagery revealed average differences for $C_{\mathrm{LANDSAT}}-C_{\mathrm{NTA}}$ of $8.6 \pm 7.0 \%$ and for $C_{\mathrm{LANDSAT}}-C_{\mathrm{CBA}}$ of $6.0 \pm 6.8 \%$ for the Bering Sea on March 13 and 21, 1988 [34]. The much larger comparable standard deviation in Table VI can be partly explained by the fact that [30] and [34] used a $25 \mathrm{~km} \times 25 \mathrm{~km}$ grid instead of a 12.5 $\mathrm{km} \times 12.5 \mathrm{~km}$ grid. This causes less smoothing of the ice concentration, a lower (higher) number of grid cells with medium (low and high) ice concentrations, and therefore an increased probability for higher and more variable ice concentration differences. This is of particular relevance in regions with leads, polynyas and/or a well-defined ice edge as is the case in [30] and our work. A third comparison between AVHRR and SSM/I ice concentrations has already been mentioned [10].

Fig. 2(a) and (b) reveals that less than $20 \%$ of all ice concentrations lie between $6 \%$ and $94 \%$, while about $80 \%$ are either close to $0 \%$ or $100 \%$ (see $N$, Table VI). The statistics might be strongly biased toward low/high ice concentrations. Therefore, the statistics have been repeated for ice concentrations between $6 \%$ and $94 \%$. Correlation coefficients decrease to below 0.8 . New values for bias (BIAS) and slope of the regression coefficient (RC), as well as the increase of the RMS error by $4 \%$ to $15 \%$ (SLA) and by $6 \%$ to $18 \%$ (ASI), point to a poor agreement between $C_{\mathrm{AVHRR}}$ and $C_{\mathrm{SSMI}}$ in this concentration range. The average difference remains unchanged for $C_{\mathrm{ASI}}$ and decreases for $C_{\text {SLA }}$, but its standard deviation increases to almost $20 \%$. Standard deviations of the average ice concentration (not shown in Table VI) decrease from about $40 \%$ to $25 \%$.

There is notable difference in the relationship between $C_{\mathrm{AVHRR}}$ and $C_{\mathrm{SSMI}}$ between April 10 and April 13 and 16, especially for ice concentrations between $20 \%$ and $80 \%$. This can be explained by the different locations (compare Fig. 1(a), green rectangles) and the associated different compatibility of SSM/I tie points to the local conditions (the AVHRR tie point $T_{\mathrm{IR} \text {,ic }}$ is estimated locally). SLA ice tie points reflect the average ice properties of the last ten days of the entire investigated area (Section III-A) and may - to a certain degree- even represent the ice properties within one or both green rectangles (large: area I, small: area II). In contrast, ASI tie points were obtained from ARTIST experiment data (Section III-B) and, therefore, are totally independent from SSM/I data used in this study. Consequently, if ice properties between area I and II differ significantly, and/or if ice tie points represent the ice properties of area I better than those of area II or vice versa, and/or if ice properties of area I and II differ from ice properties the tie points are based upon, then differences in $C_{\mathrm{ASI}}$ and $C_{\mathrm{SLA}}$ as well as in the agreement between $C_{\mathrm{AVHRR}}$ and $C_{\mathrm{SSMI}}$ are likely to occur.

A large number of grid cells shows values for $C_{\mathrm{AVHRR}}$ close to $100 \%$, while $C_{\text {SSMI }}$ takes values down to $40 \%$ (SLA) or $20 \%$ (ASI). How can this be explained?

1) The weather filter of the ASI and the SLA weather correction might have failed. This is rather unlikely because corresponding AVHRR images reveal clear-sky conditions and therefore no cloud-influence. Also, low air temperatures (common for the investigation period) favor low total water vapor content. This influence on SSM/I brightness temperatures can easily be corrected in both algorithms.

2) AVHRR tie points could have been poorly chosen. If, for instance, $T_{\mathrm{IR} \text {,ic }}$ is too high an overestimation of $C_{\mathrm{AVHRR}}$ would result. This could happen in the MIZ, where a notable amount of open water coexists with cold ice, giving IR temperatures which might already be below $T_{\mathrm{IR} \text {,ic }}$. However, for thin ice exhibiting a rather high IR temperature a higher value would be required for $T_{\mathrm{IR} \text {,ic }}$. To choose a value for $T_{\mathrm{IR} \text {,ic }}$ that is representative of different ice types across different IR temperatures is crucial and at the same time very difficult. Using the albedo instead of $T_{\mathrm{IR}}$ is expected to be a better choice in this region.

3) Fog or low-level clouds might have obscured open water areas. This would have caused lower-than surface IR temperatures and an overestimation of $C_{\mathrm{AVHRR}}$. A comparison of $C_{\mathrm{AVHRR}}$ with $T_{\mathrm{IR}}$, including the used cloud mask (not shown), reveals that about ten grid cells with 
$C_{\mathrm{AVHRR}}=100 \%$ are in fact caused by an insufficient cloud mask on April 10. Using a more sophisticated cloud mask would reduce this error.

As an example for 2) and 3) on April 13, many grid cells have $C_{\text {AVHRR values above }} 90 \%$, while $C_{\text {SSMI }}$ takes values between $20 \%$ and $70 \%$ [red symbols, Fig. 2(a) and (b)]. Both SLA and ASI identify a flaw polynya along the fast ice of Greenland. This polynya can be identified in the AVHRR channel 1 percent albedo map quite clearly (not shown). But $T_{\mathrm{IR}}$ takes values already slightly below $T_{\mathrm{IR} \text {,ic }}$ resulting in the observed high values of $C_{\mathrm{AVHR}}$. Additionally, the polynya is partly covered by high clouds not flagged by the cloud mask further increasing a potential overestimation of $C_{\mathrm{AVHR}}$.

At low ice concentrations disagreement is pronounced on April $13\left[C_{\mathrm{ASI}} \approx 0 \%\right.$ but $C_{\mathrm{AVHRR}}=0 \%$ to $45 \% ; C_{\mathrm{SLA}}=$ $0 \%$ to $70 \%$ but $C_{\text {AVHRR }}<20 \%$, red symbols in Fig. 2(a), and (b)] and on April 16 [ $C_{\mathrm{ASI}} \approx 0 \%$ but $C_{\mathrm{AVHRR}}=0 \%$ to $40 \%$; $C_{\mathrm{SLA}} \approx 0 \%$ but $C_{\mathrm{AVHR}}=0 \%$ to $25 \%$, blue symbols in Fig. 2(a) and (b)]. In case of the ASI, agreement might be improved using the good-weather threshold of $5 \%$ instead of the bad-weather threshold of 30\% (see Section III-B). However, ASI ice concentrations of April 13 and 16 have been examined for both thresholds, revealing practically no improvement. To estimate the ice concentration in the outer part of the MIZ is difficult due to the numerous ice bands [compare Fig. 1(b) and (c)]. Here, ice might have been flooded by sea water and, therefore, most likely exhibits $T_{\mathrm{IR}}$ values close to that of open water. This would result in an underestimation of $C_{\mathrm{AVHR}}$. Ice edges given by $C_{\mathrm{AVHR}}$ and $C_{\mathrm{SSMI}}$ are not in perfect agreement. On April 13, $C_{\text {SLA }}$ (not shown) reveals an ice edge where many pixels are shifted by one to two pixels relative to the ice edge given by $C_{\mathrm{AVHRR}}$, in both directions. This gives $C_{\mathrm{AVHRR}}=0 \%$ where $C_{\mathrm{SSMI}} \neq 0 \%$ and vice-versa. The corresponding map of $C_{\mathrm{ASI}}$ (not shown) reveals a more systematic shift toward the $C_{\mathrm{AVHRR}}$ ice edge, i.e., the ASI tends to underestimate ice concentrations along the ice edge.

\section{B. SAR Versus SSM/I Ice Concentration}

Correlation (regression) analysis of SSM/I and SAR ice concentrations yield coefficients of 0.84 and 0.78 (0.77 and 0.73 ) for SLA and ASI, respectively (see Table VI). Markus et al. [35] investigated ice concentrations obtained with the enhanced NASA Team algorithm (NT2, [10]) with ice concentrations derived using a different automatic SAR ice discrimination algorithm (SICA, [36]). They reported average correlation coefficients of 0.66 and 0.87 for the central Arctic and the northern Fram Strait region, respectively, for September 1996. The regions investigated in their study, however, were covered by a minimum of $40 \%$ sea ice and, at that time of the year, exhibit different surface properties compared to the data used in this study. Therefore, a direct comparison is not appropriate.

The average difference $C_{\mathrm{SAR}}-C_{\mathrm{SSMI}}$ is acceptable for both SLA (-4.4\%) and ASI (-1.5\%); however, the associated standard deviations are elevated around $21 \%$. The RMS error of the regression compares with the standard deviations $(\approx 20 \%)$. Both ice concentration algorithms tend to both under- and overestimate $C_{\mathrm{SAR}}$ for almost the entire ice concentration range. In particular, values of $C_{\mathrm{SAR}}$ between $60 \%$ and $100 \%$ coexist with values of $C_{\mathrm{ASI}}$ between $0 \%$ and $100 \%$ and of $C_{\mathrm{SLA}}$ between $20 \%$ and $100 \%$. How can this be explained?
1) Although ice concentration estimates given for ice types in Table III are based on experience gained during similar conditions in 1998, the accuracy of these values is questionable. For brash and grease ice, ice concentration estimates may differ from those in Table III. An ice concentration of $90 \%$ for brash ice seems to be too high for ice filaments along the ice edge. Repeating the SAR ice concentration analysis with a $70 \%$ concentration of brash ice would probably reduce the disagreement for high SAR ice concentrations. This would also be valid for discrepancies at low ice concentrations [see 3) and 4) below].

2) The SAR image classification itself might be improved. For April 16, for instance, to separate ice types "first-year ice" and "brash ice" was difficult. In contrast, discriminating wind-roughened open water from thin level ice or grease ice is simple due to the large difference in backscattering properties of these surface types. For all days, best classification results have been obtained for "open water." However, due to the quite large classified area (four SAR frames, i.e., $100 \mathrm{~km} \times 400 \mathrm{~km}$ for April 10 and seven SAR frames, i.e., $100 \mathrm{~km} \times 700 \mathrm{~km}$ for April 16), misclassifications can easily arise from a change of the wind vector. For instance, the small region of grease/level ice at the top of Fig. 3(a) and (b) (black/red patch) could be such a misclassification. Tests of the classification scheme described in Section III-C revealed an error of $12 \%$ to $27 \%$ - which gives a notable error in the SAR ice concentration.

At low ice concentrations $C_{\mathrm{SAR}}$ takes values between $0 \%$ and $40 \%$, while $C_{\mathrm{ASI}}$ and $C_{\mathrm{SLA}}$ take values between $0 \%$ and $90 \%$ and $0 \%$ and $80 \%$, respectively. How can this discrepancy be explained?

3) Again, ice concentration estimates given in Table III could have caused some of these discrepancies [see 1) above]. Particularly, classifying ice filaments as brash ice with $90 \%$ ice concentration could have caused many of the symbols below the line of perfect agreement in Fig. 2(f) and $(\mathrm{g})$.

4) Again, misclassifications could have caused some of the discrepancies [see 2)]. For instance, thematic SAR maps of April 13 (not shown) and April 10 and 16 reveal one major difference. A much larger area of the MIZ (not along the ice edge but in the interior) was classified as grease ice on April 13, while it was classified as brash ice, first-year ice, or level ice on April 10 and 16. These grease ice areas are a likely source for $C_{\mathrm{SAR}}$ being much smaller than $C_{\mathrm{ASI}}$ and $C_{\mathrm{SLA}}$.

5) SSM/I ice concentrations could still be biased by the weather influence. On April 16, surface wind speed, atmospheric water vapor content, and cloud liquid water content were all quite high in the investigated area [see Fig. 3(c) and (d)]. The weather filter (ASI) as well as the weather influence correction (SLA) seem not to be sufficient because both images [Fig. 3(c) and (d)] reveal an SSM/I ice edge located notably further to the west compared to the SAR ice edge. This has possibly caused many of the blue symbols above the line of perfect agreement in Fig. 2(f) and (g). The weather influence on April 10 and 13 was significantly weaker. 
So far, the statistics have been discussed for the entire ice concentration range. Because many data are situated at low/high ice concentrations (compare Section IV), the statistics have been repeated for ice concentrations between $11 \%$ and $89 \%$, i.e., for all $C_{\mathrm{SAR}}$ and $C_{\mathrm{SSMI}}$ data pairs of this range. The results are also shown in Table VI and reflect the rather poor agreement for this concentration range already visible from Fig. 2(f) and (g). Correlation and regression coefficients are below 0.5 for both algorithms.

In the part of the Greenland Sea relevant for the comparison between SAR and SSM/I ice concentrations, ice drift along Greenland can amount up to $20 \mathrm{~km}$ per day [33] and might have biased the results given in Table VI. For this reason, the comparison has been repeated for SSM/I overpasses with a maximum time difference to SAR image acquisition of less than $1 \mathrm{~h}$. The resulting statistics reveals no improvement, neither for the entire ice concentration range nor for the range $11 \%$ to $89 \%$. Consequently, ice drift may not have influenced the comparison.

\section{SUMMARY AND CONCLUSION}

Early spring Greenland Sea sea ice concentration maps obtained with the ARTIST Sea Ice algorithm (ASI) and the SEA LION algorithm (SLA) with a grid cell size of $12.5 \mathrm{~km} \times 12.5$ $\mathrm{km}$ for April 10, 13, and 16, 1999, have been presented. Both algorithms utilize the $85-\mathrm{GHz}$ channels of the Special Sensor Microwave/Imager. The ASI uses the brightness temperature polarization difference, while the SLA uses the normalized brightness temperature polarization difference (also called polarization ratio). Using $85-\mathrm{GHz}$ data requires a special consideration of the weather influence (change in brightness temperature caused by change in roughness of the sea surface and by absorption/emission in the atmosphere due to water vapor and cloud liquid water), which is much larger compared to low-frequency SSM/I data. ASI tie points include this weather influence empirically and therefore no explicit weather correction is required. SLA tie points reflect almost clear-sky conditions. Therefore, 85-GHz SSM/I brightness temperatures are explicitly corrected for the weather influence using atmospheric data taken either from low-frequency SSM/I data or from Numerical Weather Prediction model data for radiative transfer calculations.

SLA and ASI ice concentrations have been compared with ice concentrations derived from NOAA-15 AVHRR data and classified ERS-2 SAR data. Channels 1, 2, and 4 are used to estimate tie points for each AVHRR scene to be used to estimate the ice concentration $\left(C_{\mathrm{AVHRR}}\right)$ from AVHRR IR temperature. For cloud-free areas, the comparison between $C_{\mathrm{AVHRR}}$ and $C_{\mathrm{SLA}}$ as well as $C_{\mathrm{AVHR}}$ and $C_{\mathrm{ASI}}$ reveals a strong positive correlation (about 0.95 ) with corresponding linear regression values. Confining the analysis to ice concentrations between $6 \%$ to $94 \%$ generates significantly weaker correlation and regression values and with significantly larger values for RMS error and regression bias.

Sixteen ERS-2 SAR images have been classified using a supervised approach. Five classes (open water, level ice, grease ice, brash ice, and first-year ice) have been identified. By as- signing estimated ice concentrations, the SAR ice concentration $\left(C_{\mathrm{SAR}}\right)$ has been calculated. The comparisons reveal strong agreement, but not as strong as AVHRR comparisons to ASI or SLA. Again, by omitting low/high ice concentrations and confining the analysis to ice concentrations between $11 \%$ and $89 \%$, the agreement becomes poor.

Previously, SLA and ASI have been evaluated only qualitatively with independent data [8], [9]. To the best of the authors' knowledge, this is the first time that SLA and ASI ice concentrations are compared quantitatively with AVHRR IR temperature and classified SAR imagery ice concentrations. Both SLA and ASI have to be used with care for ice analysis since they each use a different approach to address the significant weather influence associated with $85-\mathrm{GHz}$ SSM/I data compared to other SSM/I data. The performance of both algorithms is similar for clear-sky (AVHRR) and cloudy (SAR) cases, which can be expected if the respective schemes used to mitigate the weather influence work correctly. However, at low ice concentrations, the SLA tends to overestimate ice concentrations, while the ASI does the opposite. The SLA needs to be improved by using more realistic atmospheric data for the weather influence correction or by discarding pixels with a high liquid water content. There is evidence that ASI ice concentrations are biased in areas where tie points fail to represent local conditions. In contrast, SLA tie points reflect average ice conditions of a certain, selectable period, reducing such bias. More data have to be investigated to cover these issues satisfactorily.

The tie point selection required to obtain $C_{\mathrm{AVHR}}$, as well as classification, colocation, and assignment of ice concentrations to classified ice types in SAR imagery, also has high error potential. Improvements that would enhance reliability of a similar comparison include: 1) applying a more sophisticated technique to obtain ice concentrations from AVHRR imagery; 2) optimizing SAR ice concentration estimation by performing the classification frame-by-frame to minimize any effects due to changes in wind vector, and by assigning more realistic ice concentrations to the classified ice types; and 3) utilizing a much larger dataset.

The Advanced Microwave Scanning Radiometer (AMSR) aboard EOS-AQUA will allow improved sea ice analysis compared to SSM/I. The main improvement will be due to the finer spatial resolution of used AMSR channels: 18.7 and $36.5 \mathrm{GHz}$. They have an FOV of $27 \mathrm{~km} \times 16 \mathrm{~km}$ and $14 \mathrm{~km} \times 8 \mathrm{~km}$ at a sampling distance of $10 \mathrm{~km}$. Since radiative properties of the surface and the atmosphere are rather similar at 85 and $89 \mathrm{GHz}$, one can benefit from the finer spatial resolution of the $89-\mathrm{GHz}$ AMSR channels (FOV: $6 \mathrm{~km} \times 4 \mathrm{~km}$, sampling distance $5 \mathrm{~km}$ ). A first attempt toward this direction has already been made by Kaleschke [37]. ${ }^{2}$ This would produce $12.5 \mathrm{~km} \times 12.5 \mathrm{~km}$ ice concentration maps (up to three times daily from SSM/I data acquired by DMSP spacecraft F13, F14, and F15) as well as 5 $\mathrm{km} \times 5 \mathrm{~km}$ ice concentration maps (AMSR data). These can serve 1) as input for comparison of modeling efforts and 2) as independent data for evaluation of other spaceborne sensors monitoring sea ice (e.g., ERS, ENVISAT, and QuikSCAT).

\footnotetext{
${ }^{2}$ See also http://www.seaice.de.
} 


\section{ACKNOWLEDGMENT}

The authors would like to acknowledge data provided by the Global Hydrology Resources Center, NASA, Huntsville, AL, European Space Agency, Esrin, Italy, Danish Meteorological Institute, Copenhagen, Denmark, and the Satellite Active Archive, NOAA, Washington DC. The input of three anonymous reviewers is greatly appreciated.

\section{REFERENCES}

[1] K. Aagaard and E. C. Carmack, "The arctic ocean and climate: A perspective," in The Polar Oceans and Their Role in Shaping the Global Environment, O. M. Johannessen, R. D. Muench, and J. E. Overland, Eds. Washington, DC.: Amer. Geophys. Union, 1994, vol. 85.

[2] P. Lemke, W. D. Hibler, III, G. M. Flato, M. Harder, and M. Kreyscher, "On the improvement of sea ice models for climate simulations: The Sea Ice Model Intercomparison Project (SIMIP)," Ann. Glaciol., vol. 25, pp. 183-187, 1997.

[3] J. P. Hollinger, R. Lo, and G. Poe, Special Sensor Microwave/Imager User's Guide. Washington, DC.: U.S. Naval Res. Lab., 1987.

[4] D. J. Cavalieri, J. P. Crawford, M. R. Drinkwater, D. T. Eppler, L. D. Farmer, R. R. Jentz, and C. C. Wackermann, "Aircraft active and passive microwave validation of the sea ice concentration from the defense meteorological satellite program special sensor microwave imager," $J$. Geophys. Res., vol. 96, no. C12, pp. 21 998-22 008, 1991.

[5] J. C. Comiso, "SSM/I ice concentrations using the bootstrap algorithm," NASA Goddard Space Flight Center, Greenbelt, MD, NASA Tech. Rep. 1380, 1995.

[6] E. Svendsen, C. Mätzler, and T. C. Grenfell, "A model for retrieving total sea ice concentration from a spaceborne dual-polarized passive microwave instrument operating near $90 \mathrm{GHz}$," Int. J. Remote Sens., vol. 8, pp. 1479-1487, 1987.

[7] D. Lubin, C. Garrity, R. Ramseier, and R. H. Whritner, "Total sea ice concentration retrieval from the $\mathrm{SSM} / \mathrm{I} 85.5 \mathrm{GHz}$ channels during arctic summer," Remote Sens. Environ., vol. 62, pp. 63-76, 1997.

[8] L. Kaleschke, G. Heygster, C. Lüpkes, A. Bochert, J. Hartmann, J. Haarpaintner, and T. Vihma, "SSM/I sea ice remote sensing for mesoscale ocean-atmosphere interaction analysis," Can. J. Remote Sens., vol. 27, no. 5, pp. 526-537, 2001.

[9] S. Kern and G. Heygster, "Sea-ice concentration retrieval in the antarctic based on the SSM/I $85.5 \mathrm{GHz}$ polarization," Ann. Glaciol., vol. 33, pp. 109-114, 2001.

[10] T. Markus and D. J. Cavalieri, "An enhancement of the NASA team sea ice algorithm," IEEE Trans. Geosci. Remote Sensing, vol. 38, pp. 1387-1398, May 2000.

[11] S. Kern, "A new algorithm to retrieve the sea ice concentration using weather-corrected $85 \mathrm{GHz}$ SSM/I measurements," Ph.D. thesis, Dept. Physics Elect. Eng., Univ. Bremen, Bremen, Germany, 2001.

[12] D. J. Cavalieri, K. M. S. Germain, and C. T. Swift, "Reduction of weather effects in the calculation of the sea-ice concentration with DMSP SSM/I,” J. Glaciol., vol. 41, pp. 455-464, 1995.

[13] M. A. Goodberlet, C. T. Swift, and J. C. Wilkersen, "Remote sensing of ocean surface winds with the special sensor microwave/imager," $J$. Geophys. Res., vol. 94, no. C10, pp. 14 547-14 555, 1989.

[14] C. Simmer, Satellitenfernerkundung Hydrologischer Parameter Der Atmosphäre Mit Mikrowellen. Berlin, Germany: Verlag, 1994.

[15] U. Karstens, C. Simmer, and E. Ruprecht, "Remote sensing of cloud liquid water," Meteorol. Atmos. Phys., vol. 54, pp. 157-171, 1994.

[16] R. Fuhrhop, T. C. Grenfell, G. Heygster, K.-P. Johnsen, P. Schlüssel, M. Schrader, and C. Simmer, "A combined radiative transfer model for sea ice, open ocean, and atmosphere," Radio Sci., vol. 33, pp. 303-316, 1998.

[17] S. Kern, "The SEA LION algorithm: A new method for medium-resolution sea ice analysis using weather-influence corrected special sensor microwave/imager $85 \mathrm{GHz}$ data," Int. J. Remote Sens., submitted for publication.

[18] B. R. Furevik, O. M. Johannessen, and A. D. Sandvik, "SAR-retrieved wind in polar regions-Comparison with in situ data and atmospheric model output," IEEE Trans. Geosci. Remote Sensing, vol. 40, pp. 1720-1732, Aug. 2002.

[19] H. Laur, P. Bally, P. Meadows, J. Sanchez, B. Schaettler, E. Lopinto, and D. Esteban, "ERS SAR calibration derivation of the backscattering coefficient sigma-nought in ESA ERS SAR PRI products," ESA, Noordwijk, The Netherlands, Doc. No. ES-TN-RS-PM-HL09 7, Sept., 1998.
[20] L. Kaleschke and S. Kern, "ERS-2 SAR image analysis for sea ice classification in the marginal ice zone," in Proc. IGARSS, Toronto, ON, Canada, June 24-28, 2002.

[21] M. P. Mäakynen, A. T. Manninen, M. H. Similä, J. A. Karvonen, and M. T. Hallikainen, "Incidence angle dependence of the statistical properties of C-band HH-polarization backscattering signatures of the Baltic sea ice," IEEE Trans Geosci. Remote Sensing, vol. 40, pp. 2593-2605, Dec. 2002.

[22] L. K. Soh and C. Tsatsoulis, "Texture analysis of SAR sea ice imagery using gray level co-occurence matrices," IEEE Trans. Geosci. Remote Sensing, vol. 37, pp. 780-795, Mar. 1999.

[23] D. A. Clausi, "An analysis of co-occurrence texture statistics as a function of grey level quantization," Can. J. Remote Sens., vol. 28, no. 1, pp. $45-62,2002$.

[24] R. M. Haralick, K. Shanmugam, and L. Dinstein, "Textural features for image classification," IEEE Trans. Syst., Man, Cybern., vol. SMC-3, pp. 610-621, Nov. 1973

[25] J. S. Lee, "Refined filtering of image noise using local statistics," Comput. Graph. Image Process., vol. 2, no. 2, pp. 380-389, 1981.

[26] M. Unser, "Recursion in short-time signal analysis," Signal Process., vol. 5, pp. 229-240, 1984.

[27] T. Kohonen, Self-Organizing Maps, ser. Springer Series in Information Sciences. Berlin, Germany: Springer-Verlag, 1997.

[28] W. J. Emery, M. Radebauch, C. W. Fowler, D. J. Cavalieri, and K. Steffen, "A comparison of sea ice parameters computed from advanced very high resolution radiometer and landsat satellite imagery and from airborne passive microwave radiometry," J. Geophys. Res., vol. 96, no. C12, pp. 22 075-22 085, 1991.

[29] G. Zibordi, V. vanWoert, G. P. Meloni, and I. Canossi, "Intercomparison of sea ice concentration from SSM/I and AVHRR data of the Ross sea," Remote Sens. Environ., vol. 53, pp. 145-152, 1995.

[30] W. J. Emery, C. W. Fowler, and J. Maslanik, "Arctic sea ice concentrations from Special Sensor Microwave Imager and Advanced Very High Resolution Radiometer satellite data," J. Geophys. Res., vol. 99, no. C9, pp. 18 329-18342, 1994.

[31] NOAA, KLM User's Guide, Rev. ed. Boulder, CO: National Environ. Satellite Data Inform. Services (NESDIS) National Climatic Data Center (NCDC), 2000.

[32] NOAA, "National Snow and Ice Data Centre (NSIDC) DMSP SSM/I brightness temperature and sea ice concentration grids for the polar regions: User's guide," NSIDC Distributed Active Archive Center, Univ. Colorado, Boulder, CO, Rev. ed., 1996

[33] W. J. Emery, C. W. Fowler, and J. Maslanik, "Satellite-derived maps of Arctic and Antarctic sea ice motion: 1988 to 1994," Geophys. Res. Lett., vol. 24, no. 8, pp. 897-900, 1997.

[34] J. C. Comiso, D. J. Cavalieri, C. L. Parkinson, and P. Gloersen, "Passive microwave algorithms for sea ice concentration-A comparison of two techniques," Remote Sens. Environ., vol. 60, pp. 357-384, 1997.

[35] T. Markus and S. T. Dokken, "Evaluation of late summer passive microwave Arctic sea ice retrievals," IEEE Trans. Geosci. Remote Sensing, vol. 40, pp. 348-356, Feb. 2002.

[36] S. T. Dokken, B. Hakansson, and J. Askne, "Intercomparison of Arctic sea ice concentration using RADARSAT, ERS, SSM/I and in-situ data," Can. J. Remote Sens., vol. 26, pp. 521-536, 2000.

[37] S. Kaleschke, private communication, 2002.

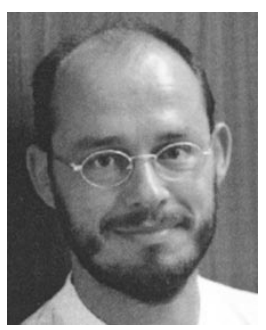

Stefan Kern received the Diploma degree in meteorology from the University of Hannover, Hannover, Germany, in 1997, and the Ph.D degree in physics from the University of Bremen, Bremen, Germany, in 2001.

After working on radiosonde and VHF radar measurements at the Institute of Meteorology and Climatology, Hannover, Germany, he joined the Institute of Environmental Physics, Bremen, Germany, in 1998, where he worked as a Graduate Research Assistant on passive microwave remote sensing of sea ice and the atmosphere. Since 2001, he has been with the Institute of Oceanography of the University of Hamburg, Hamburg, Germany, as a Research Assistant, where he has been involved in synthetic aperture radar data analysis of oceanic phenomena and multisensor sea ice studies. His research interests include data analysis and fusion of active and passive remote sensing data for polar climate system studies, remote sensing of atmospheric and oceanic phenomena, and in situ as well as helicopter-borne measurements of sea ice and snow properties. 


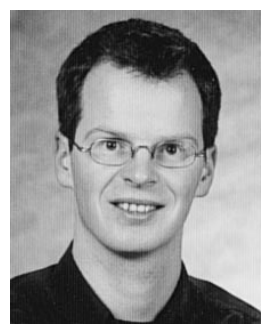

Lars Kaleschke received the M.A.Sc. degree in physics from the University of Bremen, Bremen, Germany, in 1998, where he is currently pursuing the Ph.D. degree.

He is a Graduate Research Assistant currently with the University of Bremen. His present research topic is remote sensing of sea ice and frost flowers, and the role of frost flowers for tropospheric chemistry. His research interests include active and passive remote sensing, data analysis image processing, and pattern recognition.

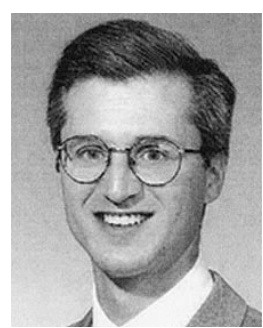

David A. Clausi (S'93-M'96) received the B.A.Sc., the M.A.Sc., and Ph.D. degrees, all from the University of Waterloo, Waterloo, ON, Canada, in 1990, 1992, and 1996, respectively.

$\mathrm{He}$ has worked in the medical imaging industry with Mitra Imaging Inc., Waterloo, ON, Canada, and later was an Assistant Professor in the Department of Geomatics Engineering at the University of Calgary, Calgary, AB, Canada. In 1999, he returned to the University of Waterloo and is currently an Associate Professor in systems design engineering. His research interests include automated image interpretation, digital image processing, and pattern recognition with applications in remote sensing and medical imaging. 